\title{
Australia's National Injury Insurance Scheme - design, challenges and opportunities
}

\author{
Andrew Fronsko \\ Territory Insurance Office, Darwin NT 0800, Australia. afronsko@tiofi.com.au,
}

This presentation will focus on history and economic theory perspectives, using benchmark comparisons across Australian jurisdictions and leveraging materials in the public domain. The aim is to assist practitioners refine and manage their NIIS schemes for long term viability and customer/participant outcomes. The presentation will look at the Genesis of National Injury Insurance Schemes in Australia - a brief history of thinking that has shaped NIIS design, scheme Design model and rationale for a NIIS including Rationale for separating the NIIS and NDIS, What the "I" in NDIS really means, the Benchmark comparison of NDIS versus NIIS design feature and the staged approach to migrate to universal accident compensation. Moving on to exploring. NIIS Implementation Update - Motor Accident Compensation including a benchmark comparison - design models in 5 Australian CTP Jurisdiction. And finally a look at Insurance Claims Management vs Disability Management before speaking about the Next steps for NIIS and integration or possible alignment opportunities with the NDIS. 